\title{
A EMIGRAÇÃO DA SOBERANIA DE RUDOLSTADT AO BRASIL NA METADE DO SÉCULO XIX
}

\author{
Rudolf Ruhe \\ Tradução de Márcio José Werle*, André Carlos Werle*** e João Klug****
}

RUHE, Rudolf. Die Auswanderung aus der Rudolstädter Oberherrschaft nach Brasilien in der Mitte des 19 Jahrhunderts. Rudolstadt: Buchdruckerei F. Mitzlaff KG, Rudolstädter Heimathefte, Heft 6/7, 1959, p. 162-181.

O destino da maior parte da emigração alemã foi desde o início a América do Norte, principalmente a região da atual nação dos Estados Unidos. $\mathrm{O}$ fato pode ser atribuído, por um lado, à política colonizatória inglesa dos séculos XVII e XVIII e, por outro, a fatores que principalmente durante o século XIX fizeram a região ser mais atrativa: liberdade de pensamento e de religião, livre constituição dos Estados, condições de direito regulamentadas e garantidas, assim como, mas não em último lugar, terras incomensuravelmente férteis que ainda não haviam sido ocupadas ou entregues pelo Congresso. Além disso, as condições climáticas agradáveis e semelhantes as da Europa central e nórdica, eram igualmente um atrativo a mais. ${ }^{1}$ Mesmo durante a Guerra Civil Americana (1861-1865) os Estados Unidos permaneceram no topo da lista dos países de imigração alemã. Neste período, entretanto, notou-se um forte recuo da emigração alemã em geral. A cota dos Estados Unidos na recepção de emigrantes alemães, que quase sempre variou entre 80 e $90 \%$, pode ser mais facilmente percebida, se a intensidade do movimento for apresentada em números. De acordo com a verificação de Monkmeier, ${ }^{2} 4.274 .310$ pessoas emigraram da Alemanha no período de 1847 até 1910, das quais, 3.888.767

\footnotetext{
* Doutorando no Programa de Pós-Graduação em História da Universidade Federal de Santa Catarina - UFSC e bolsista da CAPES. E-mail: marciojosewerle@yahoo.com.br ** Doutor em História pelo Programa de Pós-Graduação em História da UFSC.

*** Professor no Programa de Pós-Graduação em História da Universidade Federal de Santa Catarina - UFSC. E-mail: joaoklug@yahoo.com.br
} 
optaram pelos Estados Unidos, enquanto 89.268 emigraram ao Brasil, 83.227 para o Canadá, 46.689 se direcionou para o restante da América, especialmente a Argentina, 55.322 foram para a Austrália, 17.255 para a África e apenas 2.909 para a Ásia, enquanto que 190.873 emigraram com destino incerto.

Brasil e Canadá seguem em $2^{\circ}$ e $3^{\circ}$ lugar na ordem de todas as nações que receberam emigrantes, mas com muita distância em relação aos Estados Unidos. Seguindo os Estados Unidos, o Brasil sempre permaneceu em segundo lugar em importância para a emigração alemã, mesmo que, como demonstram os números, no período de 1847-1910 somente tenha uma diferença de 6.000 a mais do que o Canadá. Mas há de se notar que no caso do Canadá há o inconveniente de que os emigrantes, em muitos casos, viviam lá somente temporariamente e mais tarde fixaram residência definitiva nos Estados Unidos. Somente depois da passagem do século o Canadá foi mais e mais e mais preferido por emigrantes alemães. ${ }^{3}$

Enquanto que a colonização europeia começou muito cedo nos Estados Unidos, Portugal, que até 1822 tinha o Brasil como colônia, mantinha distante qualquer emigrante estrangeiro até o início do século XIX. Somente então se notaram no Brasil esforços para a colonização. Ainda antes da independência do Brasil, o Rei Dom João VI decretou em Portugal (1818) que fosse promovida a emigração europeia, especialmente a alemã. Mas como havia várias regalias, como a instalação gratuita e preferência por católicos, estes esforços mal apresentaram resultados. Somente quando foi afastada a condição prévia de ser católico e foi facilitado o ingresso de emigrantes de outras religiões, estabeleceram-se em 1825 e 1829 as primeiras colônias alemãs no Brasil Meridional (São Leopoldo, Rio Grande do Sul, e Santa Catarina). Apesar de tudo, o Brasil permaneceu alvo preferido de emigrantes saídos de terras romanas. ${ }^{4}$ Mas o Brasil nunca chegou a exercer uma atração extraordinária na emigração alemã, pelo fato das melhores condições climáticas para emigrantes do norte e centro europeus serem somente as províncias do sul e além disso, porque especuladores, publicitários e agentes inescrupulosos por meio de várias intrigas fizeram com que o Brasil ganhasse má fama exatamente na Alemanha, sendo constantemente objeto de veementes discussões. Mas mesmo assim o Brasil apresentou-se aos moradores empobrecidos e sem recursos das florestas de Thüringen muitas vezes a última chance para dar um futuro mais iluminado à sua desoladora condição de vida, isto devido às favoráveis ofertas de imigração ao Brasil. Por isso, no que se refere a emigração alemã, percebe-se somente em alguns anos isolados um fluxo maior: 1.955 emigrantes em 1851, $2.093 \mathrm{em}$ $1.852,1521$ em 1854, 1.837 em 1855, 3.419 em 1863, 3.486 em 1869 e 2.102 em 1881. O Brasil permaneceu privado de grandes ondas emigratórias alemãs, como as que se estenderam durante décadas em direção aos Estados Unidos. 
O destino do movimento emigratório ultramarino do antigo principado de Schwarzburg-Rudolstadt foi quase sem exceções o continente americano. Também os emigrantes de Schwarzburg privilegiaram, em sua grande maioria, a região dos Estados Unidos e somente durante a década de 50 do século XIX os esforços colonizatórios brasileiros encontraram ali considerável repercussão. Em contrapartida, todos os demais países não europeus para onde se dirigiu a emigração não eram procurados em Rudolstadt.

A emigração ultramarina saída de Scharzburg-Rudolstadt iniciou muito timidamente, pois até o ano de 1845 as cifras se desenvolveram a tal ponto que o pequeno Estado de Schwarzburg não teve importância para a política populacional. No território da antiga soberania de Rudolstadt, cuja região era formada por ambos os conselhos provinciais de Königsee e Rudolstädt, as estatísticas da quantidade de pessoas que emigraram ao ultramar indicam que no período somente uma vez o número ultrapassou os cinquenta, isto em 1841 . Mas já em 1846, os números aumentaram repentinamente, pois mais de 150 pessoas deixaram para trás sua antiga pátria e procuraram melhores condições de vida noutro lado do oceano. Em contrapartida, os anos de 1847 até 1849 apontaram novamente um leve recuo na emigração, mas que dobrou nos dois anos seguintes e em 1852 o número da emigração decuplicou. Com isso também se atingiu o ponto máximo da emigração ultramarina saída da soberania. Já em 1853 as cifras caíram novamente pela metade, quer dizer, das 1.200 pessoas de 1852 para algo em tomo de 600 pessoas no ano de 1853 . Pode-se constatar um leve aumento em 1853, mas dali em diante a emigração recuou para menos de 200 e até menos de 100 pessoas por ano. Nos anos que se seguiram, pode·se observar uma tendência de queda, devagar, mas constante, que somente é quebrada durante os anos de 1857, 1860/61 e 1867/68, mas permanecendo também nestes anos abaixo das 200 pessoas. Nos anos 70 do século XIX, houve um recuo tão grande na região de Rudolstädt que já nem se pode mais falar em movimento emigratório ultramarino. A migração de Schwarzburg-Rudolstadt não permaneceu completamente estacionada, mas nos anos que se seguiram, como nos tempos iniciais do movimento, a política populacional permaneceu sem problemas. Doravante, a crescente industrialização direcionou a população para outros caminhos e a maioria dos moradores de regiões pobres preferiu o trabalho industrial a se instalar em terras desconhecidas. ${ }^{5}$

A pesquisa de números relativamente seguros acerca da emigração de nossa região causou certas dificuldades, principalmente em decorrência de falhas na continuidade da base documental. ${ }^{6}$ Mesmo que os resultados alcançados sejam somente valores relativos, pois se baseiam muitas vezes em cálculos aproximados, ainda assim os resultados devem se aproximar da realidade. Mesmo que o material numérico da emigração ultramarina já foi trabalhado em cada lugar da soberania, referente ao período de 1834 a 1870 , 
uma restituição resumida será suficiente para a questão aqui abordada, pois aos dados relativos à emigração ao Brasil serão abordados adiante.

\section{Emigração Ultramarina 1834-1870}

\begin{tabular}{l|c|c|c|c}
\hline & $\mathbf{1 8 3 4 - 5 0}$ & $\mathbf{1 8 5 1 - 6 0}$ & $\mathbf{1 8 6 1 - 7 0}$ & $\mathbf{1 8 3 4 - 7 0}$ \\
\hline A) Conselho Estatal de Rudolstädt & & & & \\
\hline Províncias: & & & & \\
\hline 1. Rudolstädt & 146 & 459 & 75 & 680 \\
\hline 2. Blankenburg & 135 & 340 & 84 & 559 \\
\hline 3. Stadtilm & 203 & 419 & 148 & 740 \\
\hline 4. Leutenberg & 197 & 275 & 102 & 574 \\
\hline & & & & \\
\hline B) Conselho Estatal de Königsee & & & & \\
\hline Províncias: & & & & \\
\hline 5. Königsee & 253 & 1209 & 209 & 1671 \\
\hline 6. Oberweißbach & 118 & 639 & 410 & 1167 \\
\hline
\end{tabular}

A década de 1851-60 constituiu para Schwarzburg-Rudolstädt o período de maior perda populacional através da emigração ultramarina, que devido sua condição de pequeno Estado sempre era considerável. Neste mesmo período aconteceu também o recrutamento para a colonização brasileira, que encontrou animado eco especialmente na população das assim chamadas "povoações das florestas".

A colonização brasileira, desde a declaração da independência em 1822, se desenvolveu em três fases principais, de acordo com uma interpretação do ano de 1861:7

\section{I: $1824-1844 ; \quad$ II: $1845-1853 ; \quad$ III: 1854-1864.}

Durante o primeiro período os colonos europeus fundaram inicialmente em 1824 e 1825 as colônias de São Leopoldo e Santa Cruz na província do Rio Grande do Sul e a colônia de São Pedro e Vargem Grande na província de Santa Catarina, na província do Rio de Janeiro fundaram a colônia alemã de Nova Friburgo e finalmente na província da Bahia a Colônia Leopoldina. No entanto, o governo perturbou o desenvolvimento da colônia fazendo um recrutamento sob "fa1sas promessas" de colonos irlandeses e alemães para 
servir de soldados. Isso ocasionou oposições que contribuíram não somente para uma revolta em 1828, como também paralisou a emigração europeia durante vários anos. Conforme foi relatado, daquele momento até 1844 "apenas 153 novos colonos chegaram ao entroncamento da colonização (São Leopoldo)." Como este primeiro intento colonizatório do governo brasileiro foi bem barato, mas pouco apoiado eficazmente, ela nunca chegou plenamente ao embalo e alcançou pouco sucesso. Este acontecimento contribuiu essencialmente para que o assim chamado segundo período fosse iniciado com um projeto de lei no governo para a proteção e incentivo a colonização. Para este objetivo, concedeu-se em 1846 a quantia de 200000 dólares e o presidente do Rio de Janeiro exigiu também a imigração de apenas pequenas levas de imigrantes, até que os preparativos para o acolhimento, alojamento e demais prosseguimentos para grandes levas estivessem completos. Esta bem intencionada proposta contrariou, todavia, os agentes gananciosos que ao mesmo tempo já haviam atraído milhares, mas para os quais não havia nem moradias dignas, nem os meios para garantir a subsistência. Em contrapartida, por exemplo, o alemão Dr. Hermann Blumenau de Hasselfelde em Harz, guiou-se por bem outros pressupostos quando em 1850 fundou uma colônia, com seu nome, com 17 "colonos", no rio Itajaí, na província de Santa Catarina. Em 1854, a colônia contava com exatos 468 imigrantes com propriedade de terras. ${ }^{8}$ Antes de o Dr. Blumenau começar a realizar seus planos colonizatórios, ele deve ter durante anos, se ocupado com a questão da imigração e se convencido sobre as melhores possibilidades e condições para tal. Deste senhor e de sua colônia ainda voltaremos a falar. Quase ao mesmo tempo, foi fundada nesta mesma província, a colônia alemã Dona Francisca pela Sociedade Colonizadora de Hamburgo, assim como, fundações nas províncias de São Paulo, Rio de Janeiro e Espírito Santo. Ao total, no fim do " $2^{\circ}$ período colonizatório", todas estas colônias contavam em torno de 30000 imigrantes.

No "terceiro período" ocorreram na Alemanha acaloradas discussões a favor e contra a emigração para o Brasil. Esta discrepância, iniciada em parte por associações ou sociedades alemãs de emigração que ou pretendiam pôr em prática algum plano de colonização e por isso procuravam influenciar a emigração com fundamentos políticos e comerciais ou argumentar com pontos de vista filantrópicos. Os últimos, contudo, não eram infundados, de acordo com informações autênticas, especialmente no norte do país, onde dominavam condições desoladoras. Não restam dúvidas que inescrupulosos especuladores e seus cúmplices tinham a mão no jogo. Sob estas condições sofreram - se os relatos conferem - principalmente as colônias do norte do Brasil. Mesmo que algumas colônias ou colônias de determinada região não tiveram boa reputação, ainda assim estava errado espalhar tal inconveniente e atribuí-lo propositadamente e com total desconhecimento do assunto ao Brasil inteiro. 
Em comparação com isso, as vozes que favoreciam a emigração para o Brasil partiam de dois lugares fundamentalmente distintos. Alguns, interviam em favor do Brasil apoiados em informações seguras, procurando mostrar que especialmente o sul do Brasil oferecia realmente boas condições para os emigrantes trabalhadores e aplicados, que podiam no mínimo obter uma existência livre de preocupações referentes à alimentação. Já outro grupo que defendia a emigração para o Brasil queria garantir sua parte, como cúmplices e sem grandes esforços, nos lucros de inescrupulosos especuladores, impostores e outros homens obscuros. Com isso, pretendiam fornecer sem hesitação, todas as "forças de trabalho necessárias", embora muitas vezes nem conheciam seus contratantes e nem as condições do lugar de destino, para o qual eram enviados os seus conterrâneos. Já nos anos de 1847, o Jornal Geral da Emigração (Allgemeine Auswanderungs-Zeitung) ${ }^{9}$ relatou acerca do partido ou "Camarilla" existente no Brasil e que trabalhava contra a imigração alemã. A este partido pertenciam "especialmente comerciantes e criadores de escravos", para os quais pouco agradava uma "terra de trabalho livre". Ainda assim, é possível que estes mesmos membros do partido mais tarde, com intenções particulares tenham "abraçado" a causa da colonização para poder empregar mão-de-obra branca e barata nos seus negócios e de seus clientes.

Os conflitos desatados na Alemanha em torno da emigração para o Brasil também motivaram o governo de Schwarzburg a pedir, de sua parte, "informações oficiais", que foram recebidas em primeira linha do "governo Prussiano". Este enviou em 1859 um "relatório", cujo conteúdo pretendia convencer as autoridades superiores de Rudolstädt para "decididamente desaconselhar a emigração para o Brasil." 10 Sem duvida, é preciso deixar em suspenso se este relatório correspondia as partes do acontecimento, isso porque existe a suposição de que as informações fornecidas pelo representante real do Brasil foram inspiradas no então Cônsul Geral do Brasil, Johann Jackob Sturz ${ }^{11}$, o qual foi demitido pelo Brasil em 1859 e que deve ter desempenhado um papel pouco elogiável. Este relatório ainda será mencionado noutro contexto.

Em contrapartida, é muito elucidativa a descrição de um engenheiro alemão: "Brasil e a emigração alemã", o qual atuou durante nove anos como engenheiro e agrimensor no Brasil e aproveitou para dar uma "espiada nos arquivos provinciais". ${ }^{2}$ Para o autor, "o caluniar de uma nação estrangeira desmedidamente em nossa imprensa", por pessoas que "nem por ouvir falar" conheciam o país, motivou seu parecer pormenorizado. A autenticidade dos colaboradores é menos duvidosa do que os lados claros e escuros da emigração para o Brasil, assim como também é de se advertir a exagerada propaganda contraria ao Brasil e os "relatórios lisonjeiros de muitos agentes brasileiros" os quais segundo o ponto de vista do autor, agem somente com segundas intenções. São denunciados também, de forma não muito diferente, 
colonos que acreditaram "chegar ao bem·estar sem trabalho e esforço", assim como os "mandriões" e ociosos, que trocam o dinheiro subsidiado para os primeiros tempos por "cachaça barata", passando o tempo "vagabundeando e caçando", enquanto que suas mulheres e crianças trabalhavam. Em comparação com isso, muitas vezes se exigiu "leais e francos moradores da Alemanha", que não possuíssem dinheiro de auxilio, mas que fossem trabalhadores e econômicos. No entanto, podiam até ser grosseiros, desajeitados, dependentes ou bem humildes e submissos. Já este "infeliz costume trazido da pátria" seria totalmente desagradável e até ridículo. Além disso, para eles, "tudo o que não era como estavam habituados na terra natal" lhes causava medo e espanto, e muitas vezes não iam além do que eram empurrados. Entretanto, a índole dos colonos se alterava muito depois de algum tempo de convívio no país. Pois o "mais humilde sentido de servidão", saber ler escrever, conhecer versículos bíblicos, não promovem essa transformação, mas sim, autonomia e saber e pegar firme no trabalho. $\mathrm{O}$ autor sugere que o governo alemão deveria auxiliar os emigrantes "não somente com palavras", mas com um oportuno "representante dos alemães no exterior". Entretanto, seria muito difícil para um enviado "conhecer a verdadeira situação, pois exatamente a corja e a vagabundagem procuram garantir seu auxilio, enquanto que a maioria da outra parte nem necessita de sua ajuda". Pelo mesmo motivo a maioria dos relatos de viajantes deveriam ser recebido de forma crítica, pois somente procuravam na faixa litorânea, onde a "corja preferencialmente" permanece. Para finalizar, o engenheiro se ocupa ainda com o antigo Cônsul Geral Sturz, do qual the chamou a atenção "nos arquivos das províncias fardos inteiros de litografias". Por exemplo, os colonos do Rio Grande do Sul, Santa Catarina e Espírito Santo, teriam primeiramente recebido "noticias da assim chamada atividade do mencionado senhor por meio de jornais alemães" e teriam se espantado com as descrições, nas quais nem reconheciam o país, a terra e nem a si mesmos. Mas, o que mais lhes causou estranhamento foi o fato de, "segundo alguns jornalistas alemães os colonos passaram a ser escravos."

Estas contribuições confirmam a suposição de que realmente os inimigos do Brasil, por intermédio de desmedidos exageros e falsos relatórios procuravam riscar a política colonizatória brasileira, que era contrária a seus próprios planos. Apenas disso deve ter dependido a representação objetiva do nosso mencionado senhor, a qual era de atuar esclarecedoramente e de opor-se àqueles que somente se dedicaram ao problema da emigração com objetivo de lucrar. O conselho final do autor é nem emigrar e nem deixar de fazê-lo. Mas é recomendado aqueles que "tem um suportável meio de subsistência e uma razoável perspectiva de futuro" fazer o possível para não emigrar. Em contrapartida, quem tenciona fazê-lo, que tiver braços saudáveis, vontade de trabalhar e uma centelha de inteligência encontra no Brasil uma existência e 
futuro mais seguros e garantidos do que na Alemanha. Tendência parecida defendeu também o agente de Rudolstädt, Günther Fröbel, que fundou por volta de 1845 um "Escritório de Emigração" e desde 1846, além de outros escritos relacionados com a emigração, publicou o Allgemeine AuswanderungZeitung. ${ }^{13}$ Todavia, apoiou em grande medida a emigração para o Brasil porque acreditava ver ali uma eficiente ação de ajuda, especialmente para a população necessitada das florestas de Thüringen, para os quais o governo estadual parecia incapaz de ajudar. ${ }^{14}$

Se, de um lado, sempre se tentou influenciar politicamente e comercialmente o movimento emigratório, assim também, de outro lado, os círculos religiosos faziam tal tentativa. Não é objetivo de este texto analisar o papel desempenhado da igreja na história da emigração, nem a relação das diferentes religiões uma com a outra. Mas é bem significativo, por exemplo, o fato de um padre católico advertir seus fiéis que emigram para colônias brasileiras em que viviam protestantes, "porque se entregariam a este perigo para sua religião". E se este mesmo religioso se lamenta porque se proporciona aos protestantes em toda parte "direitos iguais dos de seus católicos", e que os católicos vivem com outras religiões "assim como se mistura o repolho e os nabos" 15 isto demonstra, por um lado, uma tolerância autônoma no Brasil já por volta da metade do século XIX, a qual, na Alemanha, em muitos pontos de vista, era de se desejar. Por outro lado, o fato demonstra também claramente quais eram os fundamentos da "cura de almas" de muitos religiosos em relação a emigração.

Em um memorial de 1859, claramente de origem prussiana, relatouse as condições de emigração para o Brasil e os sistemas de colonização ali implementados. ${ }^{16} \mathrm{O}$ escrito apresenta principalmente uma tendência antibrasileira, de modo que sua veracidade é questionável em muitos pontos de vista. Mas no que se refere aos diferentes métodos de colonização, faz sóbrias declarações, ainda mais que, por exemplo, isto também foi transmitido para o Allgemeine Auswanderungs-Zeitung. De acordo com o texto, existem essencialmente as seguintes oportunidades de trabalho para os emigrantes alemães:

1. Trabalho livre com propriedades;

2. Ingresso no sistema de parceria;

3. Ingresso em simples relações de trabalho.

Afirma-se no texto que os três sistemas de colonização absorveram emigrantes alemães e que são apoiados igualmente pelo governo brasileiro. No entanto, a realização dos projetos esta nas mãos ou dos governos das Províncias, ou das sociedades privilegiadas ou também de pessoas privadas. Sob esta circunstancia desenvolveram-se sem dúvida, não raramente situações 
que desestimularam os emigrantes e tiram-lhe suas esperanças. Mas este não era o sentido da política colonizatória brasileira, a qual devia principalmente promover a exploração econômica da terra e a ligação, o mais rápido possível, com o mercado mundial. No entanto, sem a imigração europeia, este plano dificilmente poderia ser realizado. Por isso, o governo se empenhou constantemente para melhorar os métodos de colonização, mas antes de tudo proteger o imigrante contra abusos e preservá-lo de gananciosos exploradores, assim como, principalmente, acabar com os traficantes de pessoas.${ }^{17}$ Entretanto, as medidas neste sentido somente aos poucos poderiam ser implementadas. A gigantesca extensão das terras, em que a "civilização" apenas se fazia presente em estreitas faixas litorâneas, colocava alguns entraves para uma eficaz vigilância.

A aquisição de terras, em via de regra, podia ser realizado pela recepção de terras devolutas ou então pela compra de terra preparada. No primeiro caso, os imigrantes deviam receber costumeiramente 100.000 a 150.000 braças quadradas (uma braça quadrada $=4,84 \mathrm{~m}^{2}{ }^{18}$ ) de terra coberta por floresta virgem, para a preparação da qual o governo provincial disponibilizaria ferramentas de trabalho e sementes, "para a duração do tempo necessário de até um ano". Além disso, ainda devia ser concedido ao colono um auxílio em dinheiro. Em 1867 o governo decretou uma "Ordem Colonial" 19 especial para a fundação de "Co1ônias Estatais". A ordem estabeleceu, em primeiro lugar, o tamanho das colônias em no mínimo $174.240 .000 \mathrm{~m}^{2}$, assim como a elaboração de um plano que distribuía a região de colonização em vilas e lotes rurais. Os lotes rurais, que estariam à venda segundo a liberdade de escolha do comprador, foram medidos em 125.000, 65.000 e, 31.250 braças quadradas, enquanto que o pagamento foi estabelecido em condições especiais. Em geral, a primeira prestação vencia no segundo ano de colonização. Aos lotes rurais pertencia também uma área de 1.000 braças quadradas de terras já desmatadas, assim como uma cabana “com espaço suficiente". O registro do título de propriedade também estava previsto. A administração da colônia estava sob responsabilidade de uma "direção" eleita, composta de um presidente, um médico e seis colonos sem dívidas. Sua função era a recepção, acomodação, auxílio e assim por diante dos novos colonos, assim como a condução e vigilância de toda administração. Mas a direção também tinha o direito de excluir colonos lentos e não sociáveis.

No ano de 1868 foram anunciadas mais facilidades para emigrantes ao Brasil, ${ }^{20}$ mas que somente vieram em favor das "pessoas acostumadas com rígido trabalho pesado, como agricultores, trabalhadores braçais e trabalhadores". Para estes se garantia livre transporte para colônias estatais ou privadas, assim como demais subsídios e auxílios. Em contrapartida, estavam completamente excluídas das colônias estatais pessoas não sociáveis ou que 
eram despachadas por suas comunidades, assim como pessoas sozinhas com mais de 50 anos, mulheres solteiras ou viúvas com crianças - a não ser que um filho de no mínimo 20 anos acompanhe a viagem.

O sistema de parceria sempre foi muito duvidoso, se bem que é exatamente acerca deste que existem mais relatos favoráveis de colonos, que frequentemente louvam os proprietários das terras. Fazia parte da natureza do sistema que no ingresso da assim chamada parceria, sempre exista uma característica relação de dependência acima de tudo em favor do proprietário. $\mathrm{O}$ parceiro, frequentemente já na Europa se comprometia contratualmente, e no Brasil recebia a plantação sob a condição de arrendamento, mas devia cuidá-lo e providenciar a colheita. O proprietário recebia a metade da colheita como compensação, enquanto que sobre a outra parte podia dispor livremente. Mas, além disso, em regra o emigrante que fez sua viagem ultramarina para o Brasil sob custos do proprietário da plantação, primeiro restituía o dinheiro que lhe fora adiantado, assim como aos pouco ia pagando as animais de trabalho e aparelhagem de trabalho. Deste modo, estavam desde o princípio sobrecarregados de dívidas, que em muitos casos só podiam ser aliviados depois de anos. E como, não raras vezes, os colonos ainda emprestavam de seus patrões o capital rendido para compras ou outros fins, a soma de suas dívidas ia aumentando e especialmente sua relação de dependência se prolongava por mais alguns anos.

Um sistema parecido foi implementado também pela "Associação Central para Colonização no Rio de Janeiro", que, todavia interessava colonizar exclusivamente com pessoas do meio rural, isto é, agricultores e trabalhadores rurais, e ofereceu, no final um "Contrato de Associação", considerável apoio. De acordo com as "instruções" da associação de novembro de 1858 estavam garantidas regularmente ao emigrante recém-chegado recepção, alimentação, moradia, e também uma mesada, até que ele mesmo tiver escolhido lugar de destino e tivesse recebido trabalho lá. Tão logo o emigrante que se comprometer a trabalhar por salário ou parceira deve renunciar a restituição dos custos de viagem. A jornada de trabalho se estabeleceu em 12 horas diárias, contadas com as horas de recreio e almoço (algo em torno de 3 horas), enquanto que domingo e feriados eram destinados totalmente ao descanso dos trabalhadores. Para além disso, os colonos recebiam roupas de trabalho para meio ano ou invés disso, a pedido, uma soma de 20 mil réis (aproximadamente 16 Reichstaler).

Mas todos emigrantes, sejam os que colonizaram a própria terra, que ingressaram nas obrigações da parceria ou demais regalias do Estado Brasileiro, ou de associações ou sociedades, entraram com isso desde o princípio numa maior ou mesma relação de dependência. Em contrapartida, os emigrantes que dirigiram ao Brasil como assalariados ou aqueles que optaram pelo sistema de "simples" relação de trabalho, puderam, em via de regra, livremente se mover 
pelo país e fazer os mais variados trabalhos. Contudo, eles também podiam entrar em relações as quais os prendiam por longos períodos comprometidos em determinado lugares, o que também levou muitos à sedentaridade.

A melhor e mais segura informação sobre as respectivas relações, as quais os emigrantes encontraram e respectivamente na quais mais tarde viveram, em geral, os próprios participantes deveriam ter sido capazes de dar. Nenhum comunicado "oficial”, relatório consular ou demais informações vindas de terceiros jamais poderiam dar uma imagem real e confiável de tal colonização da vida de seus moradores em todos seus pormenores. Exatamente a vida e progresso de imigrantes num mundo completamente novo, em grande medida, dependia da capacidade individual, capacidade de adaptação e vontade ferrenha para trabalhar, de modo que uma norma universal mal pode ser adotada. Por isso, naturalmente as cartas pessoais de imigrantes são de valor especial para a posteridade, embora também à estas nem sempre se possa ter dado confiança irrestrita. Numa consideração: "Uma palavra sobre as cartas de imigrantes em sua pátria" o Allgemeine Auswanderungs-Zeitung também abriu suas colunas para esta parte do problema da imigração. ${ }^{21} \mathrm{O}$ editor lançou em primeiro lugar uma crítica a educação escolar popular do século XIX, na qual ele pronuncia uma opinião devastadora, ao escrever: "embora nós não tenhamos aqui um público educado", mas mesmo assim muitas pessoas entre os emigrantes que "visitaram durante 8 anos completos a escola", decorou o catecismo e canções, mas em nenhuma vez tiveram "uma remota imagem da estrutura do mundo" e então aconselha: "Quem quiser saber o quão pouco a escola faz para a vida terrena, apesar do monstruoso alarido que se faz sobre isso, este deveria viajar com emigrantes alemães para a América ou Austrália... Seria realmente de se desejar que cada navio de emigrantes estivesse acompanhado de um conselho escolar. Ele saberia, na sua volta mais sobre o verdadeiro estado da educação popular alemã do que se agora tivesse lido durante 30 anos os relatórios escolares de sua província”. E se neste texto se afirma que as condições descritas nas cartas dos imigrantes, devido a sua defeituosa educação geral, são insuficientes para descrever um país ou todo um continente, isto é um fato que também se deixa comprovar em algumas cartas isoladas.

Contudo, raramente e excepcionalmente, encontraram-se cartas de emigrantes nos documentos das repartições públicas administrativas de Schwarzburg. Mas nisso, o agente de Rudolstädt Günther Fröbel publicou no Der Pilot, no encarte do Allgemeine Auswanderungs-Zeitung, e esporadicamente também nas Folhas Semanais de Rudolstädt, inúmeras cartas que lhe foram endereçadas diretamente ou vieram em suas mãos por um parente ou conhecido de um emigrante. No entanto, Fröbel escolheu para impressão intencionalmente os exemplares que, além de transmitir interesses e instrutivas notícias, também informações práticas. $\mathrm{O}$ valor documental destas cartas meramente impressas 
neste ponto não pode ser questionado, uma vez que a agência muitas vezes disponibilizou publicamente os documentos originais. É de se lamentar, apesar disso, que nem as cartas originais nem outros documentos da Agência de Günther Fröbels foram mantidos. ${ }^{22}$ Abstraindo-se de que com certeza somente uma parte das cartas foram publicadas, estes documentos também podem nos ajudar em muitos pontos de vista. Algumas provas, cujo valor político, econômico e social não podem ser questionado, são as seguintes:

Johann Georg Back, de Mellenbach. 30 de maio de 1852 .

...Deus quis que todos fossem pobres diabos aqui no Brasil! Depois do domingo do Espírito Santo começou novo jornada diária, é um trabalho fácil, com o qual conseguimos boa comida, por exemplo, arroz, pão de milho, feijão e carne todos os dias. Aqui também há boa pinga.

...disse ao Jacob Ehrhardt: ponha-te na viagem, venda tua velha terra pedregosa e venha para o Brasil... Aqui se vive sem preocupações, nenhum fardo nos oprime... Ainda existem escravos, mas isto não nos interessa, vivemos livres. Mas mesmo os escravos vivem melhor aqui do que vocês, os camponeses... ${ }^{23}$

Mais familiares de Böhlem, Mellenbach, Königsee, Rudollstadt, Wildenspring, Sitzendorf, Oberweissbach, Lichsted e outros: Santa Justa, 9 de julho de 1852.

...Nós, colonos abaixo assinados, com prazer comunicamos a nossos concidadãos da Alemanha ou a quem se interessar que após viagem de 63 dias chegamos bem aqui e fomos bem recebidos. A viagem por terra, se bem que algo difícil neste país, foi a mais cômoda possível, graças as providências de nosso Senhor, que não poupou gastos. Chegando em Santa Justa, uma das mais bonitas e ricas regiões do Brasil, encontramos nossa moradia já pronta e muitas outras em construção. Aos doentes, o senhor Braz Carneiro Bellens até ofereceu sua própria casa e acompanhado de sua esposa nos visitou diariamente. De forma alguma consideramos verdadeiras nas difamações espalhadas em folhas públicas. ${ }^{24}$

Christian Matz de Mallenbach. Colônia Sta. Justa, 4 de novembro de 1853.

...Não nos preocupamos por alojamento e distrações, pois o administrador da colônia de nosso senhor já nos esperava... Não encontramos as coisas tão encantadoras como havíamos imaginado, as primeiras 
instalações custaram muito esforço. Mas depois de instalados, pudemos plantar e colher durante o ano inteiro... Alguns produtos, por exemplo, batatas podem ser cultivados 3 a 4 vezes... Não acreditem que somos escravos aqui. Não só vivemos aqui como pessoas livres como também livres de preocupações. Acreditamos que logo teremos pago os custos da viagem. Desejo que todos os necessitados vivam tão bem quanto nós. ${ }^{25}$

C. Klinghammes de Rudolstadt. São Lourenço de Santo Amaro, Província da Bahia, 20 de dezembro de 1855.

...Com certeza não encontramos as coisas como havíamos imaginado, a região parece ainda ser muito selvagem e não cultivada. Todavia, toda família tem uma residência com varanda. As paredes vão desde o assoalho até o telhado, como é moda aqui no Brasil. Gêneros alimentícios, também os recebemos tanto quanto necessitamos... Recebemos semanalmente 12 arráteis (antiga unidade de medida de peso equivalente 429 gramas e contendo 16 onças) de fina farinha branca, da qual assamos pão e cuca, 4 arráteis de farinha, que também é uma espécie de farinha com a qual preparamos bolinhos e assamos junto do pão, 2 arráteis de arroz, 2 arráteis de açúcar, 3/4 arráteis de café, 12 de carne e 1 quartilho de vinagre, 4 arráteis de feijão, óleo de lamparina e sal. Uma cabra prenhe prestes a dar cria, mas que não devemos carnear, mas sim criar. Da mesma forma procedemos com os filhotes. A cabra nos abastece com excelente leite. Também criamos um porco e um bom número de galinhas. Somente construí um chiqueiro para o porco, o restante dos animais vive solto. Um campo para minha própria necessidade para cultivar o tamanho que quiser. Gêneros alimentícios não mais nos oprimem e se algum pobre não puder pagar, ninguém é explorado. Minha esposa tem tanto que lavar e tricotar que poderia ocupar 10 mãos. Para lavar e passar uma camisa ela recebe 6 vinténs ou 12xr ( =Kreuzer)... Cana-de-açúcar, milho, feijão são os produtos principais. Bananas, laranjas, amêndoas, figos e outras frutas do sul crescem em toda vizinhança. Ninguém até agora nos proibiu de escrever a verdade, podemos escrever o que e quando quiser. ${ }^{26}$

Franz Holle de Beeschstedt Ibicaba, 1 de fevereiro de 1856.

...se Leonhard e Gottfried estivessem também aqui e tivessem vivenciando o primeiro ano que é o mais difícil, então certamente eles também estariam seguros... Afiar serras não é um bom trabalho aqui. Colher café é bem mais fácil e melhor. Mas o café não faz nada sozinho, é preciso lidar com diversas coisas: cultivar plantas e frutos de toda sorte, 
criar porcos e outros animais. Então podemos concorrer, mesmo sendo colonos, com os mais ricos camponeses da Alemanha. Vagabundear decerto não se pode... cada ano que passa sinto que melhorei minha condição... Sou agradecido também ao agente Fröbel de Rudolstadt. Até que a natureza não se modificar, o primeiro ano é difícil e quem não tiver boa saúde vai comer capim pela raiz... Mantenho minha ordem no trabalho, mas também no comer e beber, não tão raro como na antiga pátria, onde com trabalho mais rígido tínhamos de passar fome, sobrecarregar as costas de aflição e preocupação, ao ponto de não mais saber o que fazer de tanta angústia. Aqui ninguém é castigado devido as dívidas. Por exemplo, colonos que devem ao nosso senhor Vergueiro 4000 mil réis valem diante dele tanto quanto os que tem esta quantia de crédito para com ele, desde que seja ordeiro, obediente e trabalhador. ${ }^{27}$

Ottomar Stier de Schwarzburg Porto alegre, 20 de fevereiro de 1856.

...Quando aqui cheguei recebi logo um bom cargo como administrador da imprensa alemã. Em geral comigo ocorreu tudo de bem no Brasil, mesmo no exército. Quem não é tolo, facilmente pode chegar a algo... Eu sempre advirto as pessoas para não se alistar como soldado, pois destino pior não se encontra se não souber arranjar proteção. Bem diferente é o caso de emigrantes colonos, estes são auxiliados pelo governo até sua primeira colheita. Também os artesãos recebem quase sem exceção um bom dinheiro. Algumas folhas alemãs são publicadas caluniando o Brasil, como se o governo brasileiro não cumprisse com suas obrigações. Mas isto é uma lastimável difamação. O governo, em muitos casos, fez mais do que havia se comprometido, mas os pobres emigrantes são explorados por agentes espertos donos de navios. Agora eu comecei a ensinar em alemão e aulas de piano, pois existem muitos jovens que querem aprender... Quem entende de música, mesmo sem muito jeito, é aqui um homem respeitado... A música aqui ainda está num estágio muito baixo e um músico aplicado será por isso abençoado. Ao Senhor Fröbel, meus mais sinceros cumprimentos. ${ }^{28}$

Johann Heinrich Friedrich Harz, de Horba Campinas, 1856.

...Não aconselho ninguém a emigrar, quem tiver parcialmente seu sustento deve permanecer em casa, pois o clima afeta alguns muito intensamente e os bichos-de-pé são aqui uma grande praga... Vocês me escreveram pedindo da escravidão. Não vos deixem enganar. Somos 
livres, tanto que minha mão lhes escreve. Bem que ouvimos que alguns imigrantes oriundos de Böhlen escreveram mal, eles mesmo me disseram. Mas ou uma pessoa que escreve tal coisa não bate bem da cabeça, ou tem má índole. Já no navio algumas pessoas se postaram mal, iniciaram roubalheira e brigas, de modo que alguns até tiveram de ser presos no mastro. Em nova colônia também há música, o proprietário da terra permite que dancemos e nos hospedemos em sua fazenda. ${ }^{29}$

Carl Graner, de Döschnitz

Colônia Ibicaba, Província de São Paulo, 20 de Agosto de 1856.

... Não iria trocar minha situação atual com muitos proprietários de Döschnitz. Tenho agora duas vacas, uma bezerra e um bezerro, seis porcos e uma cabra, galinhas e patos. Temos tantos gêneros alimentícios quanto precisamos... Mas certamente isto não aparece do nada, todo precisamos trabalhar bem. Mas aqui eu vou com mulher e crianças tanto para o trabalho quanto para a mesa, pois não preciso fazer aqui como fazia na Alemanha, dar à cada criança um pedacinho de pão na mão e já se preocupar de onde tirar o pão para o dia seguinte... Certamente teremos de pagar ainda por alguns anos nossa dívida, com a crescente emigração tudo ficou caro e para manter a roupa de uma família se gasta muito dinheiro... Desde que o colono cumpra suas obrigações, a sociedade se mantém no contrato, nós podemos se quisermos, uma vida inteira manter essa relação. Quem abandonar a sua colônia sem aviso prévio e saldar suas dívidas, deve pagar uma multa de 50 mil réis... ${ }^{30}$

Carl August Müller, de Döschnitz.

Colônia São Jerônimo, Província de São Paulo, 30 de outubro de 1857.

...Em 5 de agosto nosso navio baixou ancora em Santos. Nosso capitão foi a terra com um bote e trouxe um saco de laranjas e bananas, que dividiu entre nós. Vocês não podem imaginar como estas frutas eram boas... No dia 20 chegamos em nossa colônia e fomos recebidos alegremente pelo diretor, assim como dos colonos da Suíça, Holstein e Thüring, que já há vários anos vivem aqui. A colônia é maior do que Döschnitz. As moradias foram sorteadas, Biel pegou a número 4, que estava pronta, eu peguei a número 8 , que ainda não estava pronta. Para isso temos a ajuda dos antigos colonos... São casas grandes e bonitas, com janelas, portas e muito espaço. Cada família recebe seus gêneros alimentícios. 
...Também dançamos dois dias seguidos, aqui isso não dá tão nas vistas do que em Döschnitz, onde todo mundo fala a respeito. Aqui se dança para ganhar fome e antigamente, a gente muitas vezes precisava dançar para que a fome passasse. E se a Liese estivesse aqui, ela poderia preparar um café melhor do que em casa; aqui não se faz 16 xícaras com 15 grãos. Se depois disso que lhes escrevi sobre o Brasil tiverem vontade de vir, não demorem e não passem mais necessidades; mas vocês devem tomar uma decisão firme. ${ }^{31}$

Gunther Gressler

Colônia Santa Cruz do Rio Pardo, Província do Rio Grande do Sul, 22 de outubro de 1860.

As escolas daqui são precárias. Encontram-se aqui escolas do governo, nas quais recebem tudo, mesmo livros e todo o material escolar, mas a mais próxima fica a uma distância de 2 horas, então teria de deixar as crianças na casa de alguém, o que também não gostaria de fazer... Eu e alguns vizinhos queremos manter um professor aos nossos próprios custos, mas ainda não encontramos a oportunidade adequada. Por enquanto eu ou minha esposa estamos dando algumas lições à nossas crianças, mas também muitas vezes falta tempo... Assim certamente o ensino vai devagar... Cavalgar as crianças aprendem aqui mais rapidamente. Uma igreja católica com torre está sendo construída aos custos do governo... Os protestantes construíram com seus próprios meios algumas casas de oração e o salário do pastor eles mesmos pagam... Do ponto de vista religioso, o governo não se importa nem um pouco com os protestantes... Os brasileiros são muito tolerantes em questões de religião e não julgam os homens de acordo com o nome de sua religião. Em geral, acreditamos não estar longe o tempo em que os protestantes estarão em pé de igualdade com os católicos em todos os aspectos (por exemplo, construção de igrejas e padres)... ${ }^{32}$

Se mesmo que os poucos exemplos apresentados acima nem de longe dão uma imagem conclusiva e completa da vida dos que saíram das terras de Rudolstädt em direção ao Brasil, pode-se perceber que sua condição social em geral melhorou em relação daqueles que ficaram em sua pátria. Igualmente esta claro, isto se percebe através dos inúmeros exemplos, que somente o trabalho pesado, a persistência e energia ajudaram a sobrepor as dificuldades iniciais e alcançar os objetivos. Como nem todos que se juntaram a corrente emigratória geral ou despachados como importunos conterrâneos, possuíam esta necessária virtude, muitos não conseguiram se dar bem. Os resultados de sua decepção foram então amargas lamentações. 
Um instrutivo exemplo de fundação, desenvolvimento e florescer de uma colônia de imigrantes nos é propiciada pela Colônia Blumenau, no rio Itajaí da Província de Santa Catarina. ${ }^{33}$ A colônia foi fundada com somente 17 colonos no ano de 1850, pelo Dr. Hermann Blumenau, levou o nome do fundador, abrangia uma grande faixa de terra e seguia planos bem fundamentados. Em 1856 contava exatamente 468 moradores, número este que se elevou até em 1858 logo à 679 com 19 fogos. Enquanto que se pode perceber o movimento populacional permanece igual até 1859 . no ano de 1860/61 as estatísticas subitamente dobram e em 1880 os moradores da colônia chegaram algo em torno de 30.000 pessoas. Uma tabela compilação fornece a seguinte imagem acerca do movimento populacional até o não de 1861.

\begin{tabular}{l|c|c|c|c|c|c}
\hline & $\mathbf{1 8 5 6}$ & $\mathbf{1 8 5 7}$ & $\mathbf{1 8 5 8}$ & $\mathbf{1 8 5 9}$ & $\mathbf{1 8 6 0}$ & $\mathbf{1 8 6 1}$ \\
\hline Moradores & 468 & 906 & 679 & 684 & 947 & 1531 \\
\hline Fogos & 94 & 152 & 169 & - & - & - \\
\hline Famílias & - & - & - & - & - & 248 \\
\hline
\end{tabular}

As necessidades que iam surgindo iam sendo logo supridas por empresas correspondentes. Assim foram citados para o ano de 1858: 3 restaurantes, 3 moinhos de cereais, 1 serraria, 11 fábricas de farinha de mandioca, 18 fábricas de açúcar, 14 alambiques, 2 padarias, 1 cerâmica, 1 olaria, 2 ferrarias, 1 fabrica de carroças, 1 cervejaria e 1 fábrica de vinagre. Como prestação de serviços podemos citar: 1 serralheiro, 1 fabricante de espingardas e relógios, 2 alfaiates, 3 sapateiros, 4 carpinteiros, 5 marceneiros, 4 pedreiros, 2 tanoeiros, 2 seleiros, 1 torneiro, 1 balaieiro, assim como algumas costureiras e lavadeiras, mas todos também trabalham com a agricultura. Também um cigarreiro se instalou. Além disso, desde 1860 habitam na colônia 2 médicos, 1 farmacêutico e 1 parteira, enquanto que a escola recebeu "um professor com formação universal" e a cura das almas um religioso evangélico.

A existência de animais fala pela fertilidade da colônia, que, fora os animais menores e os de pena, apresentam o seguinte desenvolvimento:

\begin{tabular}{l|c|c|c|c|c}
\hline & $\mathbf{1 8 5 6}$ & $\mathbf{1 8 5 7}$ & $\mathbf{1 8 5 8}$ & $\mathbf{1 8 6 0}$ & $\mathbf{1 8 6 1}$ \\
\hline Gado & 76 & 125 & 185 & 401 & 513 \\
\hline Cavalo & 11 & 13 & 31 & 58 & 61 \\
\hline Porco & 134 & 434 & 745 & 1164 & 1097 \\
\hline
\end{tabular}


Apesar desta significativa criação de animais, o peso maior da colônia reside nas culturas do solo, o que em geral havia sido o objetivo da colonização. A colonização foi determinada em parte pelas grandes plantações, de preferência o café, cana-de-açúcar ou também algodão e erva-mate, enquanto que as colônias, como por exemplo, Blumenau fazia plantações que se assemelhavam a policultura. Assim por exemplo a região transformada em solo lavrado e cultivado até o ano de 1861 completa entendidos 1.578 .000 braças quaradas, como pastagem 60.000 , milho 200.000, cana-de-açúcar 150.000 , tubérculos 100.000 , mandioca 75.000 , café 25.000 , feijão 20.000 e fumo 5.000 braças quadradas de terra. As verduras para o consumo próprio os colonos tiravam da horta, enquanto que as frutas, como laranjas e bananas são elementos que pertencem a quase todas as colônias brasileiras.

O florescer e crescer de tal colônia dependia naturalmente em grande medida da virtude de seus moradores. Por isso havia o esforço que somente pessoas robustas trabalhadoras e de caráter firme colonizassem, que alem disso possuíssem da necessária resistência. Já foi aludido em muitos casos que muitas pessoas que se juntaram à corrente emigratória acreditavam encontrar no ultramar um "El Dorado" que lhes proporcionasse uma vida confortável e sem esforços. Da mesma forma já foi apontado que comunidades empurravam para a corrente da emigração pessoas que de alguma forma eram incômodas. Assim não é de se estranhar que, por exemplo, também da Colônia Blumenau se ouvisse queixas acerca de "patifes", "beberrões" e "preguiçosos" dos quais depois de um crime desapareciam sob os nomes trocados ${ }^{34}$. Todo o trabalhador aplicado que tiver força e resistência, que não saiu da Alemanha para aqui ficar deitado sobre o pelego... mas que tem energia e tenacidade o suficiente para sofrer um difícil, as vezes muito difícil começo de ano era em contrapartida sempre bem vindo. Mas "dos letrados exige-se uma resignação ainda maior", pois, "ele substitui os prazeres espirituais por esforços corporais, precisa não raramente entrar em relações muito subordinadas e é julgado precisamente de acordo com sua capacidade de trabalho e firmeza de caráter". ${ }^{35}$

Ao contrário de agricultores e trabalhadores rurais ou pessoas que se dedicam aos trabalhos agrícolas, que em regra imediatamente encontraram colocação, os artesãos poucas vezes encontram boas possibilidades. Trabalhadores da construção, alfaiates e sapateiros tiveram no Brasil as melhores perspectivas, mas também eram procurados padeiros, açougueiros, tanoeiros, funileiros, carpinteiro de minas, ferreiros, seleiros, oleiros. Os salários são acima da media dos praticados na Alemanha, de modo que, por exemplo, um diarista recebe algo em torno de 1,2 até 3 dólares $(1,28=1$ Taler $)$ e um pedreiro, um construtor de maquinas ou carpinteiro de minas recebiam diariamente 2 mil réis ou 3 Gulden, muitas vezes também com alimentação. Trabalhadores rurais recebem mensalmente 8 a 12 mil réis ou 6 a 9 Taler, 
sem pagar moradia, alimentação e acompanhamento médico a serviço do proprietário maior. ${ }^{36}$

A parcela maior dos moradores da Soberania de Rudolstadt que emigrou para o Brasil era do antigo Conselho Estadual Konigsee, de Schwarzburg, região em que viviam muitas pessoas que diariamente se tinham de se contorcer para conseguir a sua existência crua. Quando foi divulgado por Günther Fröbel, no início dos anos 50 do século XIX, a possibilidade de emigração livre de custos ou financiada para o Brasil, iniciou-se uma tal afluência em seu escritório de emigração, à qual ele mal e mal conseguiu dar conta. ${ }^{37}$ Frequentemente acontecia que famílias dispostas à emigrar tiveram de esperar por oportunidades posteriores. Fröbel somente confiava em empresas que prometiam decorrer organizadamente e pareciam assegurar o futuro da emigração. Apesar de seu agitado negócio, sempre esteve de olho no bem estar dos conterrâneos necessitados, de modo que ele procurou com os melhores forças se aliar com a atuação de seus agentes. O seguinte texto, que deve fornecer uma visão geral sobre a emigração para o Brasil, se restringe somente aos casos que inequivocamente se referem "ao Brasil". A cifra total pode por isso ser ainda maior, uma vez que de 1852 a 1865 cerca de 146 pessoas emigraram "sem destino" e além disso também pessoas sozinhas ou famílias podem ter deixado o país sem autorização oficial, que em todo caso podia ser obtidas. Disso, pode-se supor que no referido período cerca de 850 a 900 pessoas emigraram para o Brasil. Todavia, a emigração do território de Rudolstadt desenvolveu-se principalmente nos anos de 1852, 1853 e 1855, enquanto que para o período posterior a 1865 , isto não pode ser verificado. A propósito, depois deste momento, no melhor dos casos, aconteceu emigração esporádica para o Brasil. Mesmo que o governo de Rudolstadt ainda em 1858 considerou inoportuno um pedido do Cônsul Geral Suíço de Leipzig, de proibição formal à emigração ao Brasil, justificando com base em relatos confiáveis que ao menos "as pessoas pobres e desempregadas ao menos ali conseguiam o seu sustento". ${ }^{38}$ Mas aos poucos se mudaram suas concepções quando a Prússia proibiu em 1859 os agentes da emigração ao Brasil devido a "queixas relacionadas a triste e desoladora situação" ${ }^{39}$ Alem desta suposição expressa, havia a desconfiança que a Prússia procurou combater a emigração para o Brasil menos por causa da "situação triste e desoladora", a qual não poderia ser comprovada e tampouco ser generalizada, mas muito mais para evitar a saída maciça da força de trabalho agrícola mal remunerada. Em todo caso, as medidas prussiana fizeram com que o governo de Schwarburg estava disposta a desaconselhar "decisivamente a emigração para o Brasil" e além disso levar ao conhecimento das repartições públicas correspondentes, de tempo em tempo, advertências públicas. Quando em 1863 um "grande número de moradores" de Böhlen e Friedesdorf pediram 
Revista Esboços, Florianópolis, v. 18, n. 25, p. 273-294, ago. 2011

A Emigração da Soberania de Rudolstadt ao Brasil na metade do século XIX

por auxílio material para emigrar, seu pedido foi negado. ${ }^{40}$ Assim, tem-se a seguinte imagem acerca do período da emigração ao Brasil:

\section{Emigração da Supremacia para o Brasil}

\begin{tabular}{l|c|c|c|c|c|c|c|c}
\hline Justizamtsberzirk & $\mathbf{1 8 5 2}$ & $\mathbf{1 8 5 3}$ & $\mathbf{1 8 5 5}$ & $\mathbf{1 8 5 6}$ & $\mathbf{1 8 5 7}$ & $\mathbf{1 8 6 0}$ & $\mathbf{1 8 6 3}$ & $\mathbf{1 8 6 5}$ \\
\hline Rudolstadt & 33 & 4 & 14 & 2 & 5 & - & - & - \\
\hline Blankenburg & 8 & 6 & 4 & - & 5 & - & - & - \\
\hline Stadtilm & 6 & 9 & - & - & - & - & 6 & 4 \\
\hline Leutenberg & - & - & 1 & - & - & - & - & - \\
\hline Königsee & 197 & 121 & 68 & - & 10 & 6 & 62 & - \\
\hline Oberweissbach & 101 & 27 & 13 & - & - & - & - & - \\
\hline Supremacia & $\mathbf{3 4 5}$ & $\mathbf{1 6 7}$ & $\mathbf{1 0 0}$ & $\mathbf{2}$ & $\mathbf{2 0}$ & $\mathbf{6}$ & $\mathbf{6 8}$ & $\mathbf{4}$ \\
\hline
\end{tabular}

Conforme mencionado logo acima e como se pode ler na tabela, a maioria dos moradores que emigrou para o Brasil era da Província de Königsee. E nesta província havia algumas comunidades havia grande contingente que a deixou devido a grandes necessidades. A que esta na frente é a Höhendorf, em Böhlen, onde antigamente a tecelagem era o ramo principal da industria. ${ }^{41}$ No período de 1852 a 1865, por exemplo, pode-se verificar: Böhlen 207, Friedesdorf 59, Mellenbach 24, Schwarzburg 48, Lichte b.W. 20 e Neuhaus 75 emigrantes para o Brasil. Em contrapartida, em todas as demais povoações da soberania, com exceção da cidade de Rudolstadt, até agora nos 51 casos averiguados os números ficaram abaixo das 20 pessoas. $O$ total da emigração ultramarina desta região, até o final da década de 70 contou algo em torno de 6.000 pessoas, no qual o Brasil, como país de destino, recebeu entre 12 a 15\% enquanto que no mínimo 80 a $85 \%$ de todos os emigrantes de Schwarzburg tomaram o destino dos Estados Unidos da América. Isto corresponde a proporção da emigração de todo o Império Alemão. ${ }^{42}$

A presente visão geral acerca da colonização brasileira de cerca da metade do século XIX, especialmente do ponto de vista da emigração da Soberania de Rudolstadt, não pode, por se tratar de uma primeira tentativa para nossa região, fornecer uma ideia precisa, tampouco pretende ser conclusiva. Muitos problemas importantes que mereciam um tratamento pormenorizado foram abordados de forma superficial ou nem sequer ser abordados devido a falta de espaço. Apesar disso, pode-se assegurar como resultado que a emigração de Schwarzburg Rudolstadt para o Brasil foi fundamentada quase sem exceção 
por necessidades econômicas e por problemas sociais. Bem em contrapartida a emigração à América do Norte, na qual também contribuíram os mesmos motivos, mas havia também em muitos casos outros motivos. Igualmente resultou que exatamente as famílias com muitos filhos, desafortunadas, empobrecidas e das florestas de Thüringen estavam dispostas a passar por dificuldades do que entregar-se mais tempo a esperanças inúteis e depender de esmolas. Para estes o Brasil oferecia em todo caso uma existência livre das preocupações alimentícias, a qual com uma certa dose de esforço e persistência em muitos casos podia até conduzir à um certo bem estar. Mas finalmente as pessoas, que em novas relações sociais despertaram do "espírito de submissão", aprenderam a tomar autonomamente, agir autonomamente, mover-se livremente, assim como pensar livre e autonomamente. Nem arrogância, nem pequena burguesia, nem leis particulares de pequenos Estados ou medidas administrativas tapadas, nem estreitas fronteiras de Estados ou leis militares cruzaram desde então seu caminho e atrapalharam seu desenvolvimento. Somente a força e vontade de trabalho determinaram, em via de regra, o destino destes emigrantes.

\section{NOTAS}

I MÖNKMEIER, Wilhelm. A emigração ultramarina Alemã. Uma contribuição a historia da migração alemã, Jena, 1912, p. 194.

2 MONKMEIER, op, cit. p. 192

3 WAGNER, Vgl. H. De litoral a litoral: a emigração alemã para o Canadá. Hamburg: 1929.

4 MONKMEIER, op. cit. p. 208

5 Veja-se a este respeito: HE $\beta$, Dr. Ulrich. Condições econômicas e sociais no sudeste da Floresta de Thüringen e sua Vorland na segunda metade do século XIX. In. Rudolstädter Heimathefte, ano 4, 1958, p. 56.

6 Sobre a pesquisa do material estatístico, das fontes associadas a ele a de sua aproveitabilidade será analisado eventualmente num outro trabalho acerca e um momento posterior.

7 Algemeine Auswanderung-Zeitung (de agora em diante abreviado: AWZ). Rudolstädt, ano de | 861 , n. 39

8 Rudolstäddter Wochenblatt (de agora em diante abreviado: RWbl.), Ano de 1852, Nr. 9, AWZ, ano de $\mid 861$, n. 39. De acordo com amistosa informação da paróquia evangélica Luterana de Hasselfelde, Herman Bruno Otto Blumenau nasceu em 26 de dezembro de 1819 , filho do guarda superior de florestas (Oberförsters) Friedrich Karl BI. O livro da igreja apresenta a seguinte anotação: "reside a anos na América, no Brasil, na Colônia Blumenau,"

9 AWZ, ano 1847, n. 16.

${ }^{10}$ LA Rudolstädt, Conselho Estatal de Königsee XII, n. 55, folha 125 e seguintes.

1 Veja a este respeito: R. Ruhe, Para a História da Emigração Ultramarina da Soberania do antigo Principado Schwarzburg-Rudolstadt no século XIX - As agências de emigrantes - In: Rud. Heimathefte, 4 ano, 1958, p. 248. 
${ }^{12} \mathrm{AWZ}$, ano de 1866, n. 36 e seguintes.

${ }^{13}$ Veja-se R. Ruhe, op. cit., p. 214 e seguintes.

${ }^{14}$ Veja-se Anm, 6; aqui também podem ser analisados os motivos da emigração. Sobre a Agência de Fröbel, veja-se R. Ruhe, op. cit., p. 244 e seguintes.

${ }^{15} \mathrm{AWZ}$, ano de $1861 \mathrm{~m} \mathrm{n} .37$.

${ }^{16}$ LA Rud., Landrat. Königsee XII, n. 55, folha 177 e seguintes; E VI Ed., n. 4, folha 227.

17 Veja-se neste sentido os inúmeros relatos do AWZ, ano de I85I e seguintes.

${ }^{18}$ Há dicionários brasileiros que equivalem a braça quadrada para 3.052 metros quadrados. ( $N$. Trad.)

${ }^{19} \mathrm{AWZ}$, ano de 1867, n. 21.

${ }^{20} \mathrm{AWZ}$, ano de 1868, n. 16.

${ }^{21}$ AWZ, ano de 1859 , n. 8.

22 Veja R. Ruhe, op. cit., p. 251.

${ }^{23}$ Circular para Emigrantes I852, anexo n. 9 (= Anexo de RWbl)

${ }^{24} \mathrm{RWbl}$, ano de 1852, n. 52.

${ }^{25}$ RWbl., ano de 1853, anexo parte 1 I.

${ }^{26} \mathrm{AWZ}$, ano de $1856, \mathrm{n} .14$.

${ }^{27}$ Der Pilot, ano de 1856, n. 27 (anexo AWZ).

${ }^{28}$ Der Pilot, ano de 1856, n. 29.

${ }^{29}$ Der Pilot, ano de 1856, n. 33.

${ }^{30}$ Der Pilot, ano de 1857, n. 11 .

${ }^{31}$ Der Pilot, ano de 1858, n. 15.

${ }^{32} \mathrm{AWZ}$, ano de $\mid 861$, n. 36.

${ }^{33} \mathrm{AWZ}$, ano de 1858, n. 28; 1859, n. 40; 1861, n. 64 e 1862, n. 35.

${ }^{34}$ AWZ, ano de 1858, n. 31 , 34 e 35.

${ }^{35} \mathrm{AWZ}$, ano de 1859 , n. 40.

${ }^{36} \mathrm{RWbl}$, ano de 1852, n. 9; AWZ, ano de 1856, n. 81; I858, n. 28; Der Pilot, ano de 1857, n. 32; 1858, n. 17 e LA Rud., Conselho Estatal de Königsee XII, n. 55, folha I 27 e seguintes.

${ }^{37}$ Veja R. Ruhe, op. cit., p. 249 e seguintes.

${ }^{38}$ LA. Rud. E VI 5 d, n. 4 folha 217.

${ }^{39}$ LA. Rud. Conselho Estatal de Königsee XII, n. 55, folha I9I; RWbl., ano de I872, n. 104 e 193.

${ }^{40}$ LA. Rud. EVI e d, n. 4, folha 239.

${ }^{41}$ Veja-se a este respeito: Dr. Hans Eberhardt, Para a história dos tecelões na Königsee Oficial, in: Rud. Heimathefte, 3 ano de 1957, p. 151 e seguintes.

${ }^{42}$ Veja-se a respeito: Mönckmeier, op. cit., p. 15. 